\title{
Pulmonary capillary haemangiomatosis: a distinct entity?
}

\author{
Jason Weatherald (10 ${ }^{1,2}$, Peter Dorfmüller (10 ${ }^{3,4}$, Frédéric Perros ${ }^{3,4}$, \\ Maria-Rosa Ghigna (10 ${ }^{3,4}$, Barbara Girerd ${ }^{3,4,5}$, Marc Humbert $\mathbb{1}^{3,4,5}$ and \\ David Montani (13,4,5
}

\author{
Number 1 in the Series "Ultra-rare lung disease" \\ Edited by Sergio Harari and Marc Humbert
}

\begin{abstract}
Affiliations: 'Dept of Medicine, University of Calgary, Calgary, Canada. ${ }^{2}$ Libin Cardiovascular Institute of Alberta, Calgary, Canada. ${ }^{3}$ Inserm UMR_S 999, Hôpital Marie Lannelongue, Le Plessis Robinson, France. ${ }^{4}$ Univ. Paris-Sud, Faculté de Médecine, Université Paris-Saclay, Le Kremlin Bicêtre, France. ${ }^{5}$ Assistance Publique Hôpitaux de Paris, Service de Pneumologie, Centre de Référence de l'Hypertension Pulmonaire, Hôpital Bicêtre, Le Kremlin Bicêtre, France.
\end{abstract}

Correspondence: David Montani, Service de Pneumologie, Hôpital Bicêtre, 78 Rue du général Leclerc, 94270 Le Kremlin-Bicêtre, France. E-mail: david.montanidaphp.fr

@ERSpublications

Pulmonary capillary haemangiomatosis (PCH) is a rare condition that is clinically inseparable from pulmonary veno-occlusive disease. $\mathrm{PCH}$ can develops as a consequence of genetic mutations or pulmonary venous obstruction and remodelling. http://bit.ly/35TLAY4

Cite this article as: Weatherald J, Dorfmüller P, Perros F, et al. Pulmonary capillary haemangiomatosis: a distinct entity? Eur Respir Rev 2020; 29: 190168 [https://doi.org/10.1183/16000617.0168-2019].

ABSTRACT Pulmonary capillary haemangiomatosis $(\mathrm{PCH})$ is a rare and incompletely understood histopathological finding characterised by abnormal capillary proliferation within the alveolar interstitium, which has long been noted to share many overlapping features with pulmonary veno-occlusive disease (PVOD). But are PCH and PVOD distinct entities that occur in isolation, or are they closely intertwined manifestations along a spectrum of the same disease? The classic clinical features of both PCH and PVOD include signs and symptoms related to pulmonary hypertension, hypoxaemia, markedly impaired diffusion capacity of the lung and abnormal chest imaging with ground glass opacities, septal lines and lymphadenopathy. In recent years, increasing evidence suggests that the clinical presentation, histopathological features, genetic substrate and pathobiological mechanisms of PCH and PVOD are overlapping and usually indistinguishable. The discovery of biallelic mutations in the eukaryotic translation initiation factor $2 \alpha$ kinase 4 (EIF2AK4) gene in heritable PCH and PVOD greatly advanced our understanding of the overlapping nature of these conditions. Furthermore, recognition of $\mathrm{PCH}$ and PVOD-like changes in other pulmonary vascular diseases and in conditions that cause chronic pulmonary venous hyper-perfusion or hypertension suggests that PCH/PVOD may develop as a reactive process to various insults or injuries to the pulmonary vasculature, rather than being primary angiogenic disorders.

\section{Introduction}

Pulmonary hypertension is defined as an elevation in the mean pulmonary arterial pressure ( $\mathrm{mPAP}>20 \mathrm{mmHg}$ ), which can be caused by many conditions affecting the lungs, heart and pulmonary

This article has an editorial commentary https://doi.org/10.1183/16000617.0195-2020

Provenance: Commissioned article, peer reviewed.

Received: 02 Dec 2019 | Accepted after revision: 09 Jan 2020

Copyright $\odot$ ERS 2020. This article is open access and distributed under the terms of the Creative Commons Attribution Non-Commercial Licence 4.0. 


\section{TABLE 1 Updated clinical classification of pulmonary hypertension (PH)}

\section{PAH}

1.1 Idiopathic PAH

1.2 Heritable PAH

1.3 Drug- and toxin-induced PAH

1.4 PAH associated with:

1.4.1 Connective tissue disease

1.4.2 HIV infection

1.4.3 Portal hypertension

1.4.4 Congenital heart disease

1.4.5 Schistosomiasis

1.5 PAH long-term responders to calcium channel blockers

1.6 PAH with overt features of venous/capillaries (PVOD/PCH) involvement

1.7 Persistent $\mathrm{PH}$ of the newborn syndrome

\section{$2 \mathrm{PH}$ due to left heart disease}

2.1 $\mathrm{PH}$ due to heart failure with preserved LVEF

2.2 $\mathrm{PH}$ due to heart failure with reduced LVEF

2.3 Valvular heart disease

2.4 Congenital/acquired cardiovascular conditions leading to post-capillary PH

$3 \mathrm{PH}$ due to lung diseases and/or hypoxia

3.1 Obstructive lung disease

3.2 Restrictive lung disease

3.3 Other lung disease with mixed restrictive/obstructive pattern

3.4 Hypoxia without lung disease

3.5 Developmental lung disorders

$4 \mathrm{PH}$ due to pulmonary artery obstructions

4.1 Chronic thromboembolic PH

4.2 Other pulmonary artery obstructions

$5 \mathrm{PH}$ with unclear and/or multifactorial mechanisms

5.1 Haematological disorders

5.2 Systemic and metabolic disorders

5.3 Others

5.4 Complex congenital heart disease

PAH: pulmonary arterial hypertension; PVOD: pulmonary veno-occlusive disease; $\mathrm{PCH}$ : pulmonary capillary haemangiomatosis; LVEF: left ventricular ejection fraction. Reproduced from [1].

vasculature [1]. Pulmonary hypertension is classified into five groups according to similar pathology, pathophysiology and treatment characteristics (table 1). Group 1 pulmonary hypertension includes related diseases of the pulmonary arteries, capillaries and veins with a pre-capillary haemodynamic profile. In 1977, WAGENVOORT et al. [2] described a patient presenting with diffuse lung infiltrates and respiratory failure who, at autopsy, had "aggressive" angiomatous growth of capillary-like channels in the pulmonary interlobular septae, a condition henceforth referred to as pulmonary capillary haemoangiomatosis $(\mathrm{PCH})$. Patients with $\mathrm{PCH}$ share many similarities to those with pulmonary veno-occlusive disease (PVOD) and with pulmonary arterial hypertension $(\mathrm{PAH})$. Pathologically, $\mathrm{PCH}$ is characterised by abnormal capillary proliferation in the alveolar septae with frequent focal alveolar haemorrhage and PVOD is characterised by fibrotic narrowing and occlusion of the pulmonary veins [3].

Whether PCH is a distinct entity from PVOD has been debated over the years; however, the earliest descriptions of both diseases suggested overlapping features [4]. One of the first cases of PVOD reported by STOVin and Mitchinson [5] in 1965 noted the presence "capillary angiomatous anastamotic vessels" in the interlobular septae. Similarly, in the initial description of $\mathrm{PCH}$, WAGENVOoRT et al. [2] noted the extensive involvement of the pulmonary veins and venules "could well cause it to be confused with pulmonary veno-occlusive disease". However, other histological observations of PCH without PVOD, and the presence of $\mathrm{PCH}$-like lesions in patients without the occlusive changes in pulmonary veins suggested these could be unique conditions.

Some 26 years after the first description of PCH, the 2003 World Symposium on Pulmonary Hypertension in Venice, Italy, recognised that PCH and PVOD were clinically similar, potentially overlapping conditions $[6,7]$. The discovery of pathogenic mutations in the eukaryotic translation initiation factor $2 \alpha$ kinase 4 (EIF2AK4) gene in PCH and PVOD $[8,9]$ and recent advances in pulmonary microvascular pathobiology inform us that venous and capillary abnormalities are present across a spectrum of pulmonary vascular diseases, including PAH and chronic thromboembolic pulmonary hypertension (CTEPH) [10]. As such, 
the most recent 2018 6th World Symposium on Pulmonary Hypertension now classifies PVOD and PCH under Group 1.6: "PAH with overt features of venous/capillaries involvement" (table 1) [1]. Thus, $\mathrm{PCH}$ must be discussed within the context of PVOD and PAH. The objectives of this review are: 1) to summarise the histological features of $\mathrm{PCH}$ and PVOD; 2) to summarise potential mechanisms involved in $\mathrm{PCH}$ and PVOD pathogenesis across the spectrum of pulmonary vascular diseases; and 3) highlight the overlapping clinical features of PCH/PVOD and the potential methods of distinguishing them from $\mathrm{PAH}$.

\section{Histological features in PCH and PVOD}

The hallmark histological feature of $\mathrm{PCH}$ is abnormal alveolar capillary proliferation, defined as $\geqslant 2$ rows of capillaries within the interstitium of the alveolar walls (figure 1) [7, 11, 12]. Atelectasis and congested capillaries may also mimic this appearance; however, reticulin and CD34 staining helps distinguish the proliferative nature $[11,12]$. Foci of capillary haemangiomatosis may appear nodular at low power. These lesions have been reported to be widespread throughout the parenchyma with capillary infiltration extending into airway epithelium, bronchi, and vessel walls of the pulmonary veins and arteries $[2,7,11$, 13]. Scanning electron microscopy studies have shown a distortion of small alveolar capillaries with extensive and abnormally large capillaries budding off and overgrowing smaller ones [14]. The typical pathologic changes of PVOD are intimal fibrosis and luminal narrowing, arterialisation and/or obliteration of the septal veins and venules (figure 2) $[3,4,15]$. Patchy foci with capillary multiplication within the alveolar walls are very frequent. These $\mathrm{PCH}$-like changes are usually associated with muscularised microvessels, rather resembling arterioles $>70 \mu \mathrm{m}$ in diameter. Fresh haemorrhage and haemosiderin-laden macrophages in the alveolar spaces are usually present in PCH/PVOD [14-16]. Cytological atypia is not present in the capillary endothelial cells and mitoses are not frequently observed despite the excessive proliferation [11-13]. Intimal fibrosis and medial hypertrophy are widespread and always present in the pulmonary arteries; however, plexiform lesions and thrombotic lesions are not typically present in $\mathrm{PCH}$ or PVOD [7, 11-13]. Rare cases of PCH with vascular thrombosis and infarction have been reported [13] and eccentric intimal fibrosis within the arteries may resemble thrombotic lesions. A mild interstitial lymphocytic infiltrate and interstitial fibrosis is often observed in both PCH and PVOD [12]. The thoracic
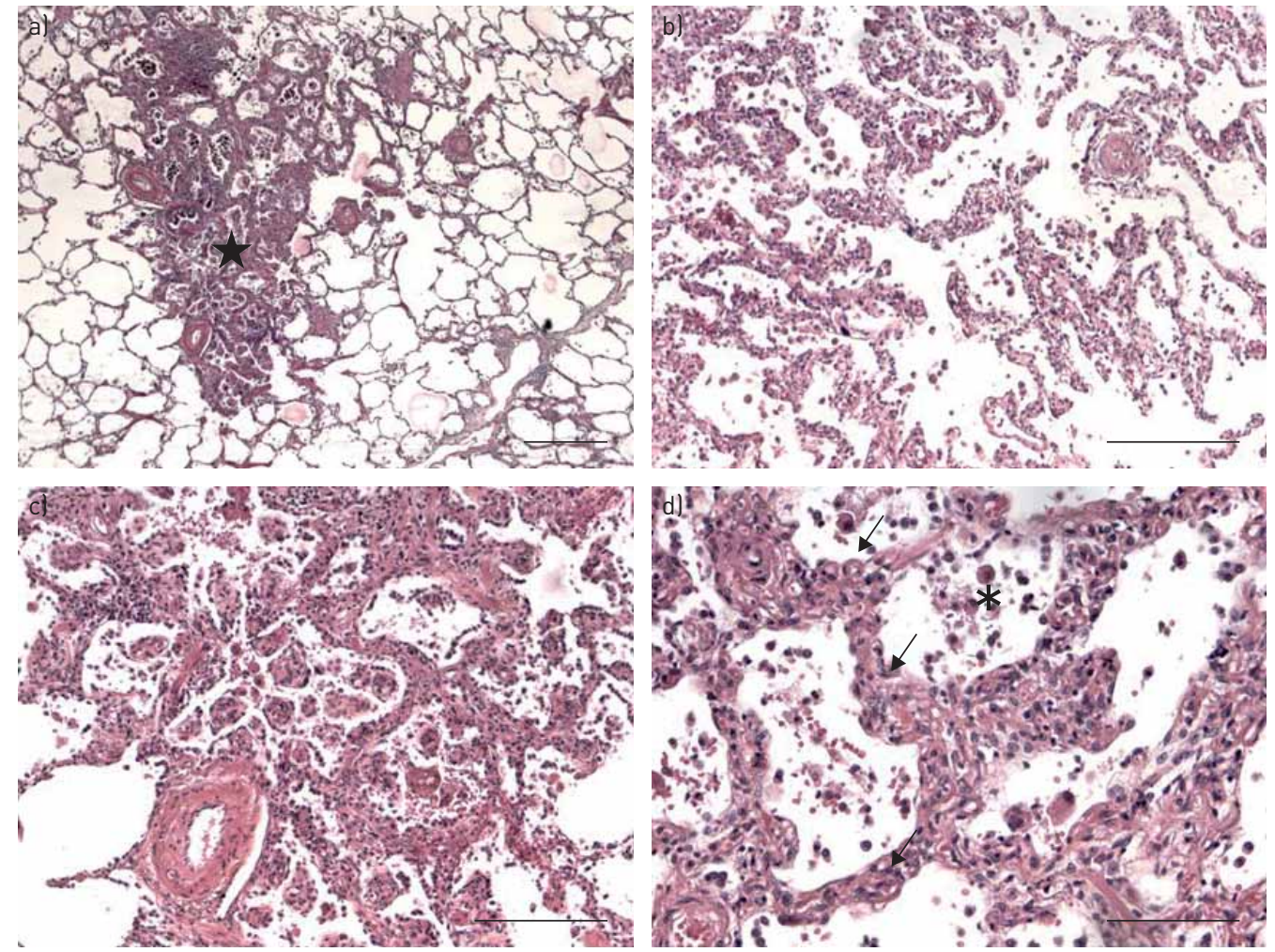

FIGURE 1 a, b) Capillary haemangiomatosis foci are readily identified within lung parenchyma (star). c) They are characterised by the increase of the cell density, close to remodelled vessels. d) Alveolar septa are thickened with dilated and/or multiplication of capillaries (arrows). Increased cellularity is characterised by affluence of inflammatory cells within the alveolar septa. Endoalveolar collections of hemosiderin-laden macrophages are also visible (asterisk). Scale bars: al $500 \mu \mathrm{m}$; b) $200 \mu \mathrm{m}$; c) $200 \mu \mathrm{m}$; d) $100 \mu \mathrm{m}$. 

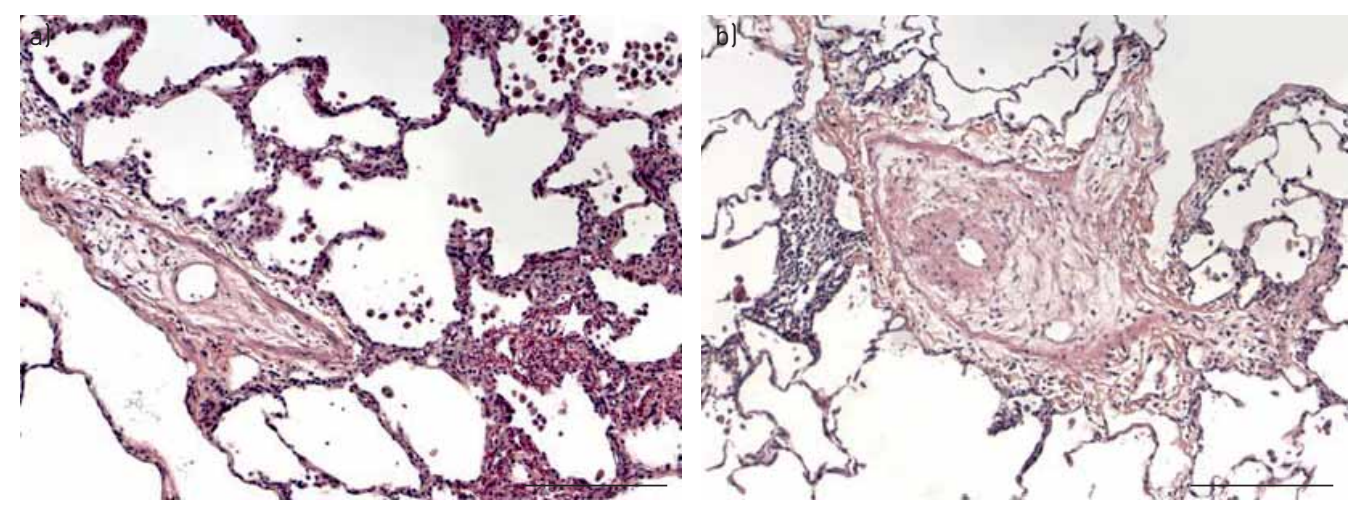

FIGURE 2 Pulmonary veno-occlusive disease. al Small pulmonary veins are markedly remodelled, showing fibro-oedematous increase of the intima, leading to significant narrowing of the vascular lumen. b) Alveolar septa appear thickened with increase of the cellularity and congestion. Scale bars: $200 \mu \mathrm{m}$.

hilar and mediastinal lymph nodes are often enlarged due to lymphatic congestion from the extensive lymphatic vessel involvement in the interlobular septae, transformation of sinuses by capillary-like vascular channels and fibrosis, follicular hyperplasia and intrasinusal haemorrhage [17].

\section{Mechanisms of disease in PCH and PVOD: two entities or a common final pathway?}

Arguments for splitting PCH and PVOD are mostly based on histological observations that pulmonary venous obstruction is not observed in all cases of PCH and some cases of PVOD do not demonstrate the marked capillary proliferation typical of PCH. Infantile and paediatric cases of PCH without the intimal fibrosis and occlusive pulmonary venous changes typically observed in PVOD have also been described $[18,19]$. Similarly, histological changes of PCH can occur in adults without venous remodelling [20]. Nevertheless, these are likely to be variable manifestations along a spectrum of the same process. In a large autopsy series of 35 cases, Lantú́foul et al. [12] observed that $80 \%$ of cases classified as PCH had pulmonary venous obstruction and $73 \%$ of cases classified as PVOD had significant capillary proliferation, illustrating that there is considerable histopathological overlap. The presence of less pronounced capillary proliferation may have gone unrecognised in some cases of PVOD lacking electron microscopy to analyse vascular casts $[12,14]$. Furthermore, PCH lesions may be multifocal and patchy through the lung [21], so lack of systematic tissue sampling could overlook PCH-like foci in cases initially diagnosed as PVOD.

Identification of EIF2AK4 genetic mutations as the cause of familial PCH and PVOD strongly support the notion that these are histopathological manifestations of the same disease $[8,9]$. The first familial cases of PCH were described by LANGLEBEN et al. [22] in 1988, in whom an autosomal recessive pattern of inheritance was suspected. In this series of three French-Canadian siblings, histological analysis of the lungs at autopsy showed widespread capillary proliferation, including penetration into the alveolar spaces and venules; however, medial thickening and intimal fibrosis of the veins was noted [22]. In 2014, EYRIES et al. [9] used whole-exome sequencing to identify biallelic mutations in the EIF2AK4 gene on chromosome 15 in 13 families with histologically confirmed diagnoses of PVOD in at least one family member, most of whom had PCH-like changes. In the same year, BEST et al. [8] identified two loss-of-function mutations in EIF2AK4 in two brothers affected with $\mathrm{PCH}$, with confirmation of asymptomatic carrier status in each of their parents. Novel mutations in EIF2AK4 gene were also identified in two additional patients with $\mathrm{PCH}$ without a family history. Familial PCH/PVOD due to biallelic EIF2AK4 mutations demonstrates an autosomal recessive inheritance pattern $[8,9,23,24]$. In biallelic EIF2AK4 mutation carriers, penetrance is likely to be nearly complete by the age of 50, as supported by the careful analysis of several families [9] as well as from long-term follow-up of biallelic EIF2AK4 mutations carriers [25]. The relentless natural history of PCH/PVOD was illustrated in a patient with EIF2AK4 mutations and two affected sisters. She demonstrated progressive disease and disability over less than 10 years from mild exercise limitation, moderately reduced diffusing capacity for carbon monoxide $\left(D_{\mathrm{LCO}}\right)$, hypoxaemia, normal resting haemodynamics and mild pulmonary vascular disease at lung biopsy to a complete PCH/PVOD phenotype characterised by severe dyspnoea at rest, marked $D_{\mathrm{LCO}}$ reduction, severe hypoxaemia, end-stage pulmonary hypertension with characteristic PCH/PVOD histology on lung explants at the time of lung transplantation [25].

EIF2AK4 mutations are found in nearly all $\mathrm{PCH} / \mathrm{PVOD}$ patients with a family history, but are also identified in $8.6-25 \%$ of sporadic cases of PCH/PVOD (figure 3) $[9,26,27]$. EIF2AK4 encodes a serinethreonine kinase known as general control nonderepressible 2 (GCN2), that phosphorylates the $\alpha$-subunit 


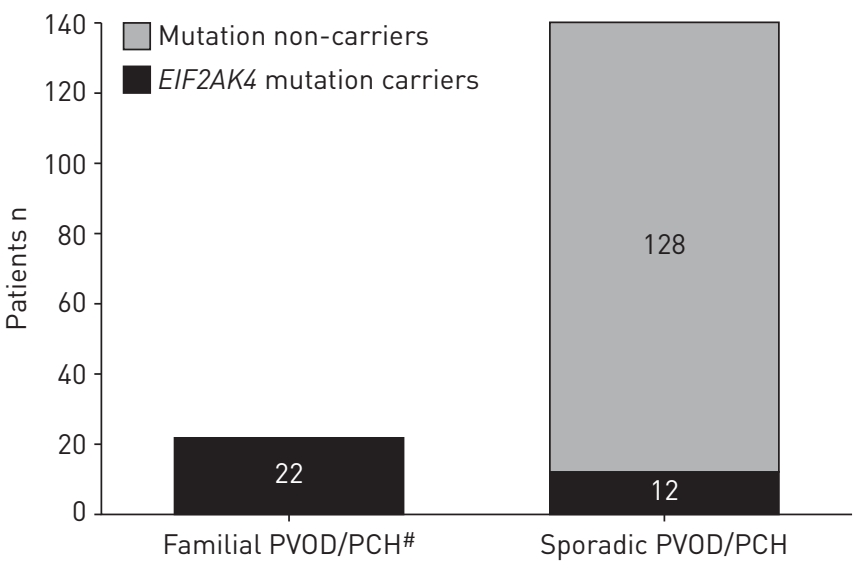

FIGURE 3 Prevalence of biallelic eukaryotic translation initiation factor $2 \alpha$ kinase 4 (EIF2AK4) mutations in patients with familial pulmonary capillary haemangiomatosis $(\mathrm{PCH}) /$ pulmonary veno-occlusive disease (PVOD) and sporadic PCH/PVOD in the French Pulmonary Hypertension Network Registry. " : from 14 different families.

of eukaryotic translation initiation factor $(\mathrm{eIF} 2 \alpha)$ under amino acid deprivation, leading to preferential synthesis of stress proteins $[9,28,29]$. GCN2 alters gene expression and promotes immune tolerance through inhibition of an inflammatory response to cell apoptosis $[9,30]$. Reduced GCN2 expression results in dysfunctional angiogenesis and remodelling in $\mathrm{PCH} / \mathrm{PVOD}$ via mechanisms that are incompletely understood [28]. Biallelic mutations in EIF2AK4 lead to markedly decreased expression of GCN2, however PCH/PVOD non-carriers of EIF2AK4 also show significant reductions in GCN2 expression, as do patients with PAH without major venous remodelling [28]. Rats exposed to monocrotaline, mitomycin $\mathrm{C}$ and cyclophosphamide, which have been linked to PCH/PVOD pathogenesis $[31,32]$, also demonstrate markedly reduced or absent GCN2 expression [28]. Decreased GCN2 expression across a range of pulmonary vascular diseases, irrespective of EIF2AK4 mutation status, not only implicates an important role of GCN2 the pathobiology of PAH and PCH/PVOD but suggests that these conditions belong to a clinical and anatomical spectrum. Recent data from our group indicate that GCN2 loss-of-function negatively regulates bone morphogenetic protein (BMP)-dependent Smad 1/5/9 signalling in pulmonary endothelial cells, underscoring possible biological similarities between heritable PAH and $\mathrm{PCH} / \mathrm{PVOD}$ [33]. We showed, in vitro, that GCN2 loss-of-function negatively regulates BMP-dependent Smad 1/5/9 signalling in human primary pulmonary microvascular endothelial cell cultures (hPMEC). This molecular relationship was confirmed, in vivo, in the lungs of a newly created transgenic rat model knock out for Eif2ak4 ( $\Delta 152 \mathrm{Ex} 1 / \Delta 152 \mathrm{Ex} 1)$. We found a four-fold decrease in Smad 1/5/9 phosphorylation in knock-out rats. Since those rats do not have spontaneous pulmonary hypertension, the decrease in Smad $1 / 5 / 9$ phosphorylation is not the mere consequence of high pulmonary artery pressures. It appears in this "pure" background (same genetic background, same environment) that GCN2 deficiency robustly decreases Smad 1/5/9 phosphorylation. This regulation may be mediated through GCN2-dependent repression of chordin, a natural extracellular antagonist of BMP signalling [34]. Moreover, GCN2 inhibition induced a dramatic increase in hPMEC proliferation, which is highly relevant of PCH genesis. Interestingly, BMP9 treatment was able to block this exuberant proliferation, suggesting it may be considered as potential therapeutic option for PCH/PVOD.

Among a large cohort of patients with confirmed or suspected PCH/PVOD, carriers of bi-allelic mutations in EIF2AK4 were younger at diagnosis compared to non-carriers (median age 26 years versus 60 years) and had a 1:1 sex ratio compared with a male predominance in EIF2AK4 mutation non-carriers [35]. In addition to being older, PCH/PVOD patients lacking mutations in EIF2AK4 frequently had occupational exposure to organic solvents, such as trichloroethylene $(42 \%)$ or chemotherapeutic agents, such as mitomycin C or cyclophosphamide (10\%), which are risk factors for PCH/PVOD [35, 36]. Thus, clinical phenotypes of PCH/PVOD in mutation carriers and non-carriers differ in important ways, highlighting how variable predispositions and pulmonary vascular injury can converge to result in a pathological pattern of $\mathrm{PCH} / \mathrm{PVOD}$. Interestingly, the extent of pulmonary arterial and venous remodelling and the distribution of PCH lesions also differ by EIF2AK4 mutations status [28]. Carriers of EIF2AK4 mutations demonstrate more patchy $\mathrm{PCH}$-like foci whereas non-carriers demonstrate more diffuse $\mathrm{PCH}$-like changes (figure 4).

Other yet-unknown genetic mechanisms may be present in some PCH/PVOD cases. A series with three siblings affected by $\mathrm{PCH}$ in infancy [37] and another family with $\mathrm{PCH}$ and no identified EIF2AK4 mutation in the study by BEST et al. [8] had autosomal dominant transmission. A $16 \mathrm{q}$ deletion in the 

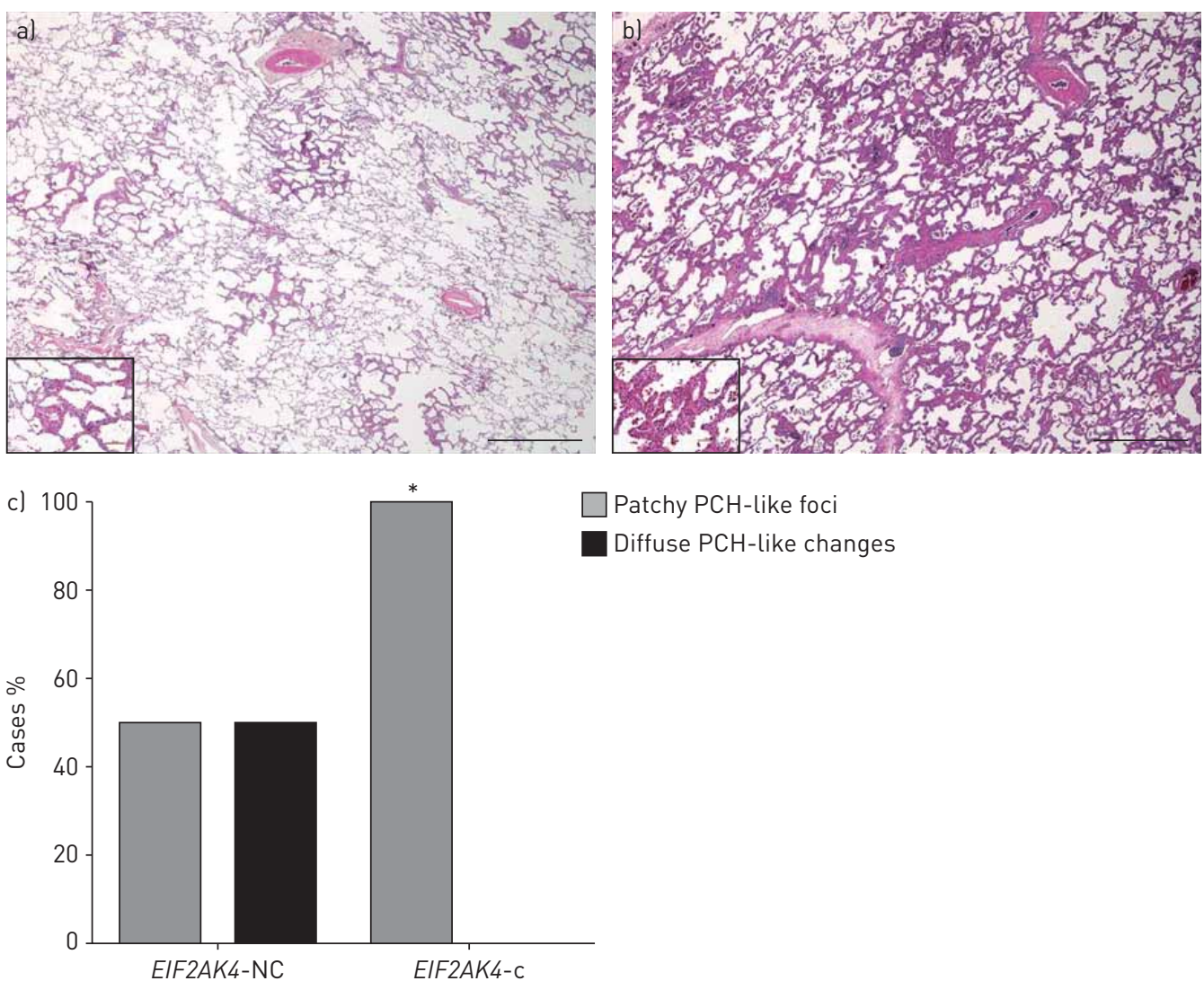

Patchy PCH-like foci

Diffuse PCH-like changes

FIGURE 4 Interstitial remodelling patterns in pulmonary veno-occlusive disease (PVOD) eukaryotic translation initiation factor $2 \alpha$ kinase 4 (EIF2AK4) mutation carriers and non-carriers. a) EIF2AK4 mutation carrier with patchy pulmonary capillary haemangiomatosis (PCH)-like foci (inset) (haematoxylin-eosin staining). b) EIF2AK4 mutation non-carrier with more diffuse $\mathrm{PCH}$-like remodelling (inset) (haematoxylin-eosin staining). Scale bars $=1000 \mu \mathrm{m}$. c) EIF2AK4 mutation carriers display a significantly higher degree of patchy $\mathrm{PCH}$-like foci $(p=0.014)$, whereas non-carriers show instead more diffuse $\mathrm{PCH}$-like remodelling. EIF2AK4-C: PVOD EIF2AK4 mutation carriers; EIF2AK4-NC: PVOD EIF2AK4 non-carriers. *: $p<0.05$. Reproduced from [28] with permission.

region for the FOXF1 gene, which has previously been associated with alveolar capillary dysplasia and misalignment of pulmonary veins in children, is the only other mutation linked to $\mathrm{PCH}$, described in a neonate diffuse capillary proliferation without venous obstruction or occlusive changes [38]. Heterozygous mutations in the Bone Morphogenetic Protein Receptor 2 gene (BMPR2) are found in the majority of families with heritable PAH [39-42]. Mutations in BMPR2 are also present in approximately $25 \%$ of PAH patients without a family history [43]; however, pathogenic BMPR2 mutations were not identified among 60 patients with PCH/PVOD [26]. A del44C mutation in BMPR2 was reported in a patient with PVOD without any capillary abnormalities on histology [44]; however, EIF2AK4 mutation status was not known since this case was published in 2003, before the discovery of the role of EIF2AK4 in PCH/PVOD.

Platelet-derived growth factor (PDGF)-B and PDGF receptor- $\beta$ (PDGFR- $\beta$ ) have also been implicated in the pathogenesis of PCH lesions with increased expression of PDGF-B and PDGFR- $\beta$ in perivascular cells, type II pneumocytes and endothelial cells within PCH lesions $[45,46]$. PDGFR- $\beta$ is also over-expressed in the pulmonary artery smooth muscle cells and endothelial cells of patients with idiopathic PAH [47], as well as in the arteries and veins of patients with systemic sclerosis-associated PAH and in PVOD [48]. Once again, the common importance of PDGF across the spectrum of PAH to PCH/PVOD suggests considerable overlap in the underlying mechanisms of disease. The use of imatinib, an inhibitor of PDGFR- $\beta$, has been associated with clinical improvements in several cases of PCH/PVOD [49-53], which may be due at least in part to its effects on pulmonary venous tone and post-capillary resistance [54]. However, no prospective controlled trials of imatinib in PCH/PVOD have been performed and a significant publication bias may exist with regards to imatinib's effectiveness in isolated cases or case series. Imatinib also resulted in modest clinical improvements in $\mathrm{PAH}$; however, it was ultimately not approved for clinical use due to deleterious side effects [55-57]. However, given the lack of alternative treatment options, further well-designed clinical studies of imatinib in PCH/PVOD would be interesting. 
The occurrence of PCH/PVOD lesions in patients with systemic sclerosis [58-62], systemic lupus erythematosus [63], Takayasu arteritis [64] and post-lung transplantation [65, 66], suggest that $\mathrm{PCH}$ and PVOD may be the end result of other poorly understood inflammatory or immune-mediated mechanisms of vascular injury and remodelling.

\section{Is PCH a primary or reactive process?}

Although isolated PCH may occur in rare cases, an emerging hypothesis is that proliferative capillary lesions develop in reaction to chronic post-capillary obstruction. Recently, using microvascular corrosion casting, scanning electron microscopy and micro-computed tomography, NEUBERT et al. [67] suggested that capillary haemangiomatosis develops as a consequence of pulmonary venous narrowing, post-capillary pressure overload and shear stress, leading to capillary sprouting and intussusceptive neoangiogenesis in the capillaries (figure 5). Further supporting this hypothesis, $\mathrm{PCH}$-like lesions are well described in other conditions that incite secondary pulmonary venous remodelling and venous obstruction due to chronic pulmonary venous hypertension. For example patients with left heart failure with reduced or preserved ejection fraction develop pulmonary venous intimal thickening and remodelling that resembles PVOD [68], while others have found PCH-like lesions in patients with left-sided valvular heart disease, hypertrophic cardiomyopathy or dilated cardiomyopathy with severe pulmonary venous congestion [69-72]. Interestingly, unilateral PCH-like foci also occur in the left lungs of patients with congenital heart defects that result in decreased right lung perfusion and hyper-perfusion or congestion of the left lung. One case described PCH in the left lung of a patient with PH and surgically repaired Scimitar syndrome (corrected anomalous right pulmonary vein drainage to left atrium, closure of ventricular septal defect and ligature of patent ductus arteriosus) [73]. The post-operative catheterisation showed complete obstruction of the right pulmonary venous return with absent antegrade perfusion of the right lung, resulting in chronic hyper-perfusion of the left lung and hypoplasia of the right lung. There were extensive changes typical of PVOD and $\mathrm{PCH}$ in the left lung with only slight pulmonary arterial hypertrophy but no pulmonary venous or capillary changes in the right lung. Another 4-year-old with a congenital right pulmonary artery stenosis demonstrated unilateral $\mathrm{PCH}$ in the left lung on biopsy, presumably from
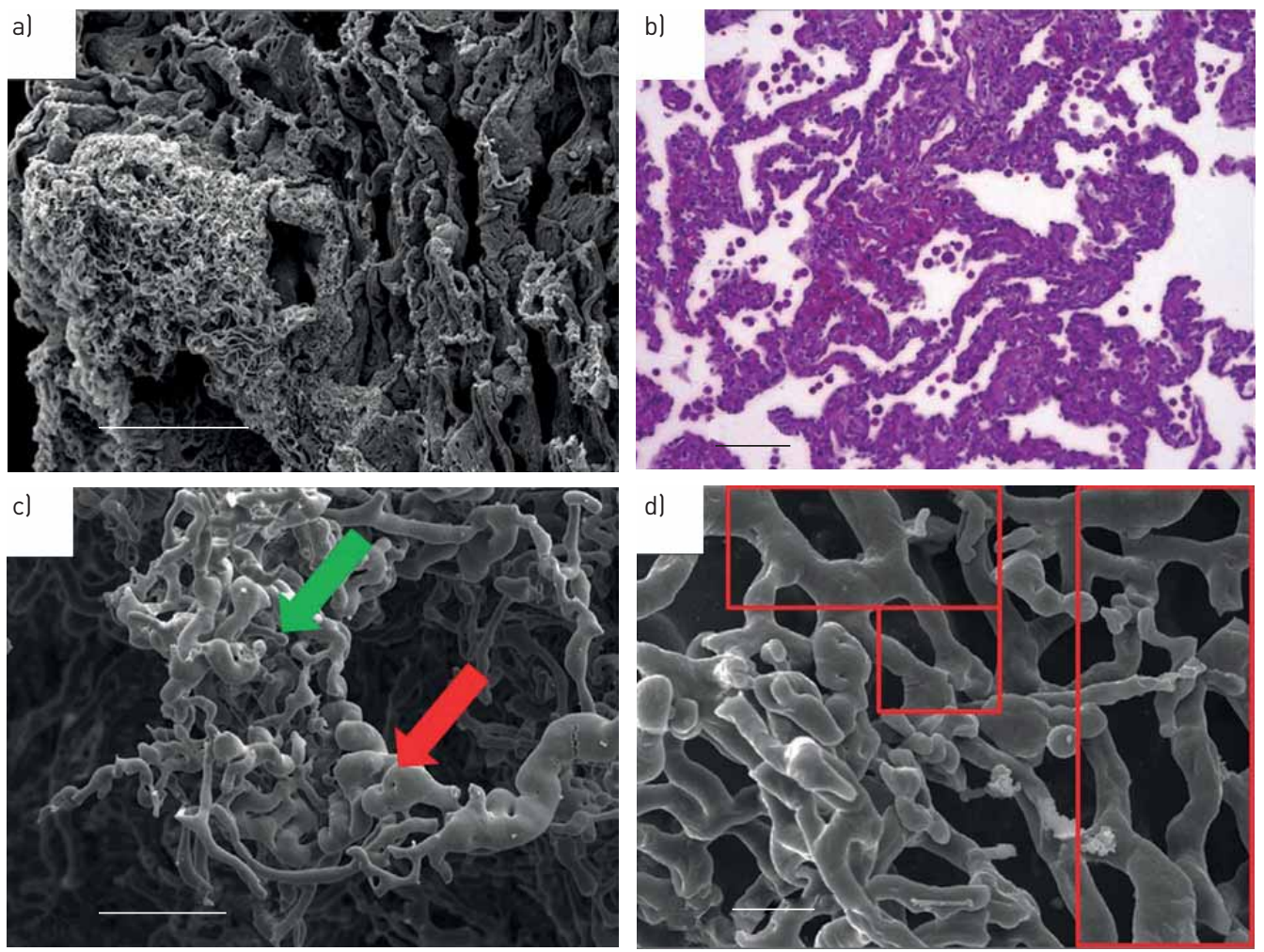

FIGURE 5 Structure and architecture of pulmonary veno-occlusive disease (PVOD) and pulmonary capillary haemangiomatosis (PCH). Prominent and back-to-back proliferation of capillaries in an area with $\mathrm{PCH}$ a) by scanning electron microscope and b) in a complementary haematoxylin-eosin stain. c, d) Scanning electron microscope following microvascular corrosion casting of affected lung tissue reveals capillary neo-formation by sprouting (green arrow in c) and intussusceptive vascular pillars (red arrow in c) next to non-remodelled pulmonary capillaries (red frames in d). Scale bars: a) $200 \mu \mathrm{m}$; b) $100 \mu \mathrm{m}$; c) $100 \mu \mathrm{m}$; d) $20 \mu \mathrm{m}$. Reproduced from [67] with permission. 
congestion or hyper-perfusion [74]. In total, these cases support the hypothesis that PCH-like foci develop as a reactive process to chronically elevated pulmonary venous and capillary pressure, whether the primary disturbance is in the pulmonary veins or further "downstream" (figure 6).

Classic histological features of PCH and PVOD occurring in seemingly different pulmonary vascular diseases also argues in favour of a reactive mechanism, in which the systemic bronchial circulation likely plays an important role. For example, $\mathrm{PCH}$-like foci, venous intimal fibrosis and arterialisation of pre-septal venules are histopathological features of the microvascular disease in CTEPH patients who have persistent pulmonary hypertension after pulmonary endarterectomy or inoperable distal disease, and in experimental CTEPH models [75]. The PCH-like lesions in CTEPH develop in close topographical association with segmental or subsegmental pulmonary arteries that had arterial thromboembolic occlusion. These capillary and venous changes in CTEPH are associated with anastomoses and shunting between the bronchial circulation and the pulmonary venous circulation [75]. Similarly, in PAH patients, systemic bronchial circulation anastomoses are seen with pulmonary arteries, capillaries and veins. The extent of bronchial artery hypertrophy and increased bronchial microvessel density are highly related to the degree of muscular hypertrophy and intimal fibrosis in pulmonary veins [76]. Furthermore, substantial $\mathrm{PCH}$-like changes were demonstrated in $86 \%$ of patients with sickle-cell disease along with bronchial hypervascularisation and venous thickening in the majority patients [77]. Therefore, exposure of the pulmonary venous circulation to higher bronchial circulation pressure and flow likely precipitate venous remodelling and secondary $\mathrm{PCH}-$ like changes [67].

\section{The inseparable clinical presentation of PCH and PVOD}

Patients with $\mathrm{PCH}$ present with nonspecific symptoms and signs and, in fact, it is not possible to distinguish PCH from PVOD based on clinical features. This is not surprising given the considerable histopathological and mechanistic overlap discussed above. Conversely, in clinical practice, differentiating $\mathrm{PCH} / \mathrm{PVOD}$ from $\mathrm{PAH}$ is a more clinically relevant question. However, while the clinical distinction is important, in reality, discriminating $\mathrm{PCH} / \mathrm{PVOD}$ from $\mathrm{PAH}$ as separate pathological entities can be difficult, since there can be considerable involvement of the pulmonary veins and capillaries in patients with PAH due to connective tissue disease or even in BMPR2 mutation carriers [62, 76].

Most patients with PCH/PVOD report symptoms related to high pulmonary arterial pressure and right ventricular dysfunction, such as dyspnoea, oedema and fatigue. In a pooled analysis of 64 cases of $\mathrm{PCH}$, haemoptysis occurred in approximately one-third of patients [78], which was higher than reported in a large case series of PVOD patients [79]. Haemoptysis also occurs in PAH patients, particularly in BMPR2 carriers, which is due to the degree of bronchial vessel remodelling [76]. Spontaneous pneumothorax has been reported in patients without clinically evident pulmonary hypertension but with $\mathrm{PCH}$-like foci on

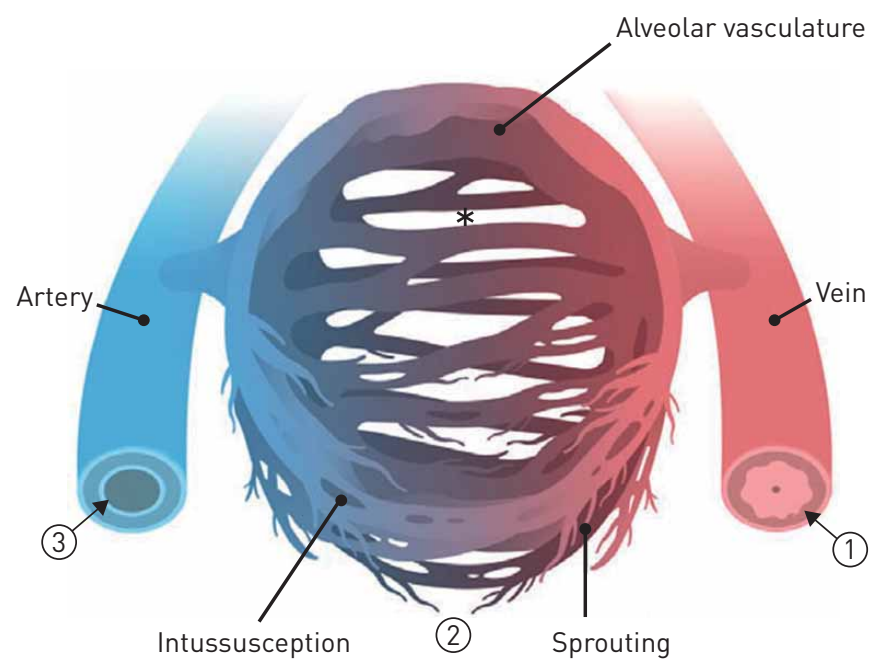

FIGURE 6 Pathogenesis of vascular remodelling in pulmonary veno-occlusive disease (PVOD). 1) Marked fibrosis of the intima and hypertrophy of the media lead to occlusion of the pulmonary postcapillary vasculature. 2) Venous occlusions cause increasing blood pressure in the pulmonary capillaries (*). Pressure overload induces excessive neoangiogenesis by sprouting and intussusceptive pillar formation likely driven by increased flow and shear stress, which results in the formation of pulmonary capillary haemangiomatosis $(\mathrm{PCH})$. 3) Congestion of the pulmonary capillary and postcapillary vasculature result in pulmonary hypertension associated with subsequent sclerotic remodelling of pulmonary arteries and arterioles. Reproduced from [67] with permission. 
lung histology [80-82]. A history of occupational exposures to solvents like trichlorethylene or to chemotherapeutic agents is much more frequent in patients with PCH/PVOD than PAH [35, 36]. Hypoxaemia is more marked in PCH/PVOD than in PAH and the diffusion capacity for carbon monoxide $\left(D_{\text {LCO }}\right)$ is markedly reduced, to a greater degree than in PAH [79]. However, the degree of hypoxaemia and $D_{\mathrm{LCO}}$ reduction does not distinguish between PCH and PVOD [83]. Cardiopulmonary exercise testing may be useful as exercise capacity is lower and dyspnoea intensity during exercise is more severe in $\mathrm{PCH} /$ PVOD patients compared with matched $\mathrm{PAH}$ patients due to higher ventilatory demand, higher minute ventilation/exhaled $\mathrm{CO}_{2}$ and physiological dead space (dead space/tidal volume), more severe gas exchange impairment and earlier onset lactic acidosis [84].

The features of PCH on chest computed tomography are also indistinguishable from PVOD and include: 1) hilar and mediastinal lymphadenopathy; 2) poorly circumscribed centrilobular ground glass nodular opacities; and 3) smooth thickening of the interlobular septae (figure 7) [79, 85, 86]. Having two or three of these computed tomography features has a sensitivity of $75 \%$ and specificity of $84.6 \%$ for PCH/PVOD.
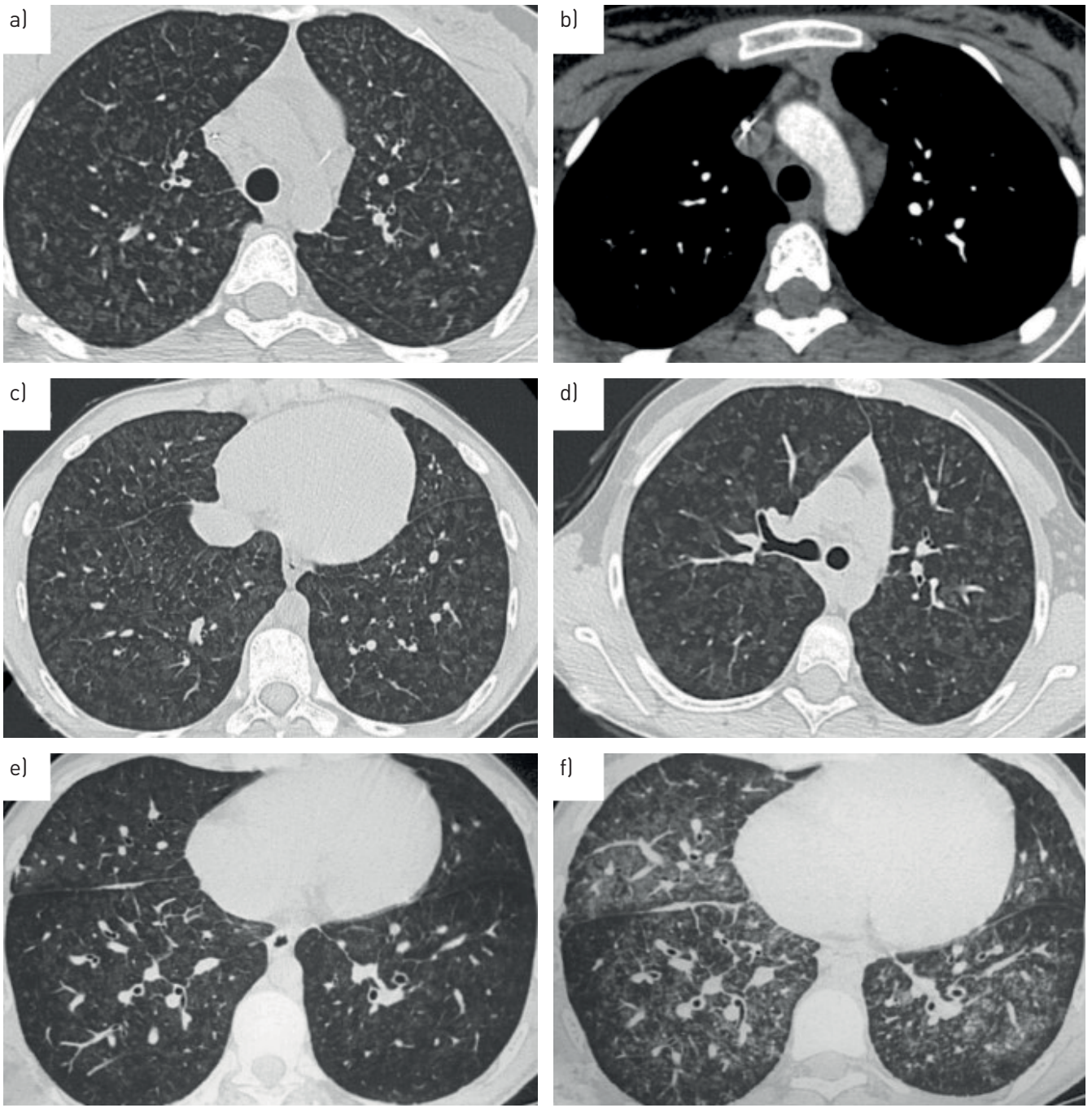

FIGURE 7 High-resolution computed tomography scan of the chest in patients with pulmonary capillary haemangiomatosis and/or pulmonary veno-occlusive disease. a) Ground-glass opacities with centrilobular pattern, poorly defined nodular opacities, and septal lines in an adult carrier of eukaryotic translation initiation factor $2 \alpha$ kinase 4 (EIF2AK4) bi-allelic mutations. b) Mediastinal lymph node enlargement in an adult carrier of EIF2AK4 bi-allelic mutations. c) A paediatric case carrying EIF2AK4 bi-allelic mutations. d) A paediatric case not carrying an EIF2AK4 bi-allelic mutation. e and f) The chest of an EIF2AK4 mutation carrier before initiation of specific therapy for pulmonary arterial hypertension showed mild abnormalities with septal lines and ground-glass opacities (e); high resolution tomography of the chest was performed 2 months after initiation of endothelin receptor antagonists for rapid worsening dyspnoea and showed a substantial increase of radiological abnormalities evocative of pulmonary oedema (f). Reproduced from [35] with permission. 
These classic computed tomography features correspond to the lymph node congestion, capillary infiltration/ proliferation, and venous remodelling in the interalveolar septae and focal alveolar haemorrhage observed on histology [79]. A small study of three patients with predominant $\mathrm{PCH}$ on histology and three patients with predominant PVOD suggested that ground glass nodule diameter may be larger in patients with $\mathrm{PCH}$ compared to patients with predominant PVOD changes [83]. However, the clinical relevance of this is unclear. Pleural effusions may also be present in PCH/PVOD but are usually small.

Bronchoscopy can be useful in certain situations to distinguish patients with suspected PCH/PVOD from PAH. As PCH and PVOD frequently have occult alveolar haemorrhage, identification of haemosiderinladen macrophages in bronchoalveolar lavage (BAL) fluid $[87,88]$ or even in expectorated sputum analysis [89] is suggestive of PCH/PVOD over a diagnosis PAH. Practically, bronchoscopy is seldom needed and may be poorly tolerated due to the frequent presence of severe hypoxaemia. Open lung or thoracoscopic lung biopsies or transbronchial biopsies are not recommended to establish the diagnosis of PCH/PVOD over $\mathrm{PAH}$ because it remains a high-risk procedure in these frail patients [87, 90]. In most cases, the typical radiographic features, very low $D_{\mathrm{LCO}}$ and disproportionate hypoxaemia are adequate to diagnose $\mathrm{PCH} / \mathrm{PVOD}$ in a patient with precapillary pulmonary hypertension.

Genetic testing can be helpful to distinguish PCH/PVOD from PAH, particularly when there is a supportive family history, as EIF2AK4 mutations are uncommon in heritable PAH and BMPR2 mutations uncommon in PCH/PVOD [26, 91, 92]. The family tree and transmission pattern can be helpful in suggesting the specific pathology, as PCH/PVOD due to biallelic EIF2AK4 mutations are transmitted in an autosomal recessive pattern and there is often consanguinity, whereas heritable PAH due to BMPR2 mutations are transmitted via an autosomal dominant pattern with incomplete penetrance. Only rarely are EIF2AK4 mutations found in patients with suspected idiopathic $\mathrm{PAH}$ and no other suggestive features of $\mathrm{PCH} / \mathrm{PVOD}$ on imaging or histology [91]. In one study, patients with clinically suspected idiopathic PAH but with biallelic EIF2AK4 mutations tended to be younger with lower $D_{\mathrm{LCO}}$, even when classic computed tomography features were not present [91]. Among patients clinically diagnosed with PAH who were $<50$ years old and with a $D_{\mathrm{LCO}}<50 \%$ predicted, biallelic EIF2AK4 mutations were present in $53 \%$. Furthermore, patients with biallelic EIF2AK4 mutations did not respond to vasodilator therapies, indicating such patients had PCH/PVOD rather than PAH [91]. Since EIF2AK4 mutations are found in about $20 \%$ of sporadic cases of PCH/PVOD, a family history is not a prerequisite to genetic testing [9]. However, since the majority of PCH/PVOD cases do not carry EIF2AK4 mutations [26, 35], the sensitivity of genetic testing is likely to be low, especially in older patients. Therefore, negative genetic testing does not exclude PCH/PVOD but identification of biallelic EIF2AK4 mutations is highly supportive of the diagnosis.

The differentiation of PCH/PVOD from PAH is of utmost therapeutic importance, since the prognosis is poor in PCH/PVOD and the use of PAH-targeted therapies in PCH/PVOD is usually ineffective and can result in pulmonary oedema $[3,35,93-95]$. The pathophysiology of pulmonary oedema in these patients is thought to be related to proximal arterial vasodilation and increased pulmonary blood flow from the effect of PAH medical therapies, which results in increased capillary hydrostatic pressure in the face of down-stream obstructed pulmonary veins. A systematic review of 64 cases of PCH/PVOD treated with various types and doses of $\mathrm{PAH}$ therapies described improvements in 6-min walk distance and pulmonary vascular resistance in some cases, but pulmonary oedema was reported in 30 patients [95]. In a study by MonTANi et al. [35], $90 \%$ of the 94 patients with PCH/PVOD had received PAH medical therapies but only three out of 47 patients with a follow-up assessment had achieved satisfactory clinical responses, despite statistically significant improvements in 6-min walk distance, cardiac index and pulmonary vascular resistance. Pulmonary oedema occurred in 23\% of EIF2AK4 mutation carriers and $21 \%$ of non-carriers in that study. Patients with underlying connective tissue disease and suspected $\mathrm{PAH}$ are also prone to developing pulmonary oedema with prostacyclin therapy [96], which may reflect their known propensity to develop pulmonary venous remodelling [62]. The development of severe, life-threating or even fatal pulmonary oedema from $\mathrm{PAH}$ therapies is well described and cannot be predicted by the presence or absence of clinical response in haemodynamics or 6-min walk distance. As such, these medications are not recommended in patients with known or suspected PCH/PVOD and the only potential treatment option is lung transplantation.

\section{Conclusions}

$\mathrm{PCH}$ is a histological finding that rarely exists in isolation and which shares nearly universal overlap with PVOD. The common risk factors, identical genetic substrate and indistinguishable clinical presentations of PCH and PVOD necessitate their consideration as a single disease and may warrant a uniform terminology to reduce confusion and heterogeneity in future clinical studies. However, since PCH/PVOD features occur across the spectrum of pulmonary vascular diseases and in many other conditions, establishing a single, precise definition may prove difficult. The current grouping of PCH/PVOD under 
"PAH with overt features of venous/capillary involvement" is logical and the use of PAH targeted therapies should be avoided or used with extreme caution in such patients. There is currently no effective treatment for $\mathrm{PCH} / \mathrm{PVOD}$ other than lung transplantation, emphasising the dire need for new innovative therapies in this rare and devastating condition.

Conflict of interest: J. Weatherald reports grants, personal fees and non-financial support from Janssen Inc. and Actelion, personal fees and non-financial support from Bayer, personal fees from Novartis, and grants from Alberta Lung Association Canadian Vascular Network, European Respiratory Society and Canadian Thoracic Society, outside the submitted work. P. Dorfmüller has nothing to disclose. F. Perros has nothing to disclose. M-R. Ghigna has nothing to disclose. B. Girerd has nothing to disclose. M. Humbert reports personal fees and non-financial support from Acceleron, grants and personal fees from Bayer and GSK, and personal fees from Actelion, Merck and United Therapeutics, outside the submitted work. D. Montani reports grants and personal fees from Actelion and Bayer, and personal fees from GSK Pfizer, MSD and Chiesi, outside the submitted work.

\section{References}

1 Simonneau G, Montani D, Celermajer DS, et al. Haemodynamic definitions and updated clinical classification of pulmonary hypertension. Eur Respir J 2019; 53: 1801913.

2 Wagenvoort CA, Beetstra A, Spijker J. Capillary haemangiomatosis of the lungs. Histopathology 1978; 2: 401-406

3 Montani D, Lau EM, Dorfmüller P, et al. Pulmonary veno-occlusive disease. Eur Respir J 2016; 47: 1518-1534.

4 Pietra GG, Edwards WD, Kay JM, et al. Histopathology of primary pulmonary hypertension. A qualitative and quantitative study of pulmonary blood vessels from 58 patients in the National Heart, Lung, and Blood Institute, Primary Pulmonary Hypertension Registry. Circulation 1989; 80: 1198-1206.

5 Stovin PG, Mitchinson MJ. Pulmonary hypertension due to obstruction of the intrapulmonary veins. Thorax 1965; 20: $106-113$.

6 Simonneau G, Galiè N, Rubin LJ, et al. Clinical classification of pulmonary hypertension. J Am Coll Cardiol 2004; 43: 5 S-12S.

7 Pietra GG, Capron F, Stewart S, et al. Pathologic assessment of vasculopathies in pulmonary hypertension. J Am Coll Cardiol 2004; 43: 25S-32S.

8 Best DH, Sumner KL, Austin ED, et al. EIF2AK4 mutations in pulmonary capillary hemangiomatosis. Chest 2014; 145: 231-236.

9 Eyries M, Montani D, Girerd B, et al. EIF2AK4 mutations cause pulmonary veno-occlusive disease, a recessive form of pulmonary hypertension. Nat Genet 2014; 46: 65-69.

10 Humbert M, Guignabert C, Bonnet S, et al. Pathology and pathobiology of pulmonary hypertension: state of the art and research perspectives. Eur Respir J 2019; 53: 1801887.

11 Havlik DM, Massie LW, Williams WL, et al. Pulmonary capillary hemangiomatosis-like foci. An autopsy study of 8 cases. Am J Clin Pathol 2000; 113: 655-662.

12 Lantuéjoul S, Sheppard MN, Corrin B, et al. Pulmonary veno-occlusive disease and pulmonary capillary hemangiomatosis: a clinicopathologic study of 35 cases. Am J Surg Pathol 2006; 30: 850-857.

13 Faber CN, Yousem SA, Dauber JH, et al. Pulmonary capillary hemangiomatosis. A report of three cases and a review of the literature. Am Rev Respir Dis 1989; 140: 808-813.

14 Schraufnagel DE, Sekosan M, McGee T, et al. Human alveolar capillaries undergo angiogenesis in pulmonary veno-occlusive disease. Eur Respir I 1996; 9: 346-350.

15 Heath D, Segel N, Bishop J. Pulmonary veno-occlusive disease. Circulation 1966; 34: 242-248.

16 Heath D, Reid R. Invasive pulmonary haemangiomatosis. Br J Dis Chest 1985; 79: 284-294.

17 Thomas de Montpréville V, Dulmet E, Fadel E, et al. Lymph node pathology in pulmonary veno-occlusive disease and pulmonary capillary heamangiomatosis. Virchows Arch 2008; 453: 171-176.

18 McGovern E, McNally P, O'Sullivan M, et al. Infantile pulmonary capillary haemangiomatosis: a lethal form of pulmonary hypertension. Cardiol Young 2016; 26: 663-668.

19 White CW, Sondheimer HM, Crouch EC, et al. Treatment of pulmonary hemangiomatosis with recombinant interferon alfa-2a. N Engl J Med 1989; 320: 1197-1200.

20 Kobayashi H, Otsuki Y, Yamaguchi M, et al. An autopsy case of pulmonary capillary hemangiomatosis with an electron microscopy study. Am J Case Rep 2019; 20: 1551-1557.

21 Erbersdobler A, Niendorf A. Multifocal distribution of pulmonary capillary haemangiomatosis. Histopathology 2002; 40: 88-91.

22 Langleben D, Heneghan JM, Batten AP, et al. Familial pulmonary capillary hemangiomatosis resulting in primary pulmonary hypertension. Ann Intern Med 1988; 109: 106-109.

23 Girerd B, Weatherald J, Montani D, et al. Heritable pulmonary hypertension: from bench to bedside. Eur Respir Rev 2017; 26: 170037.

24 Tenorio J, Navas P, Barrios E, et al. A founder EIF2AK4 mutation causes an aggressive form of pulmonary arterial hypertension in Iberian Gypsies. Clin Genet 2015; 88: 579-583.

25 Montani D, Dorfmüller P, Girerd B, et al. Natural history over 8 years of pulmonary vascular disease in a patient carrying biallelic EIF2AK4 mutations. Am J Respir Crit Care Med 2018; 198: 537-541.

26 Eyries M, Montani D, Nadaud S, et al. Widening the landscape of heritable pulmonary hypertension mutations in paediatric and adult cases. Eur Respir J 2019; 53: 1801371.

27 Girerd B, Montani D, Jaïs X, et al. Genetic counselling in a national referral centre for pulmonary hypertension. Eur Respir J 2016; 47: 541-552.

28 Nossent EJ, Antigny F, Montani D, et al. Pulmonary vascular remodeling patterns and expression of general control nonderepressible 2 (GCN2) in pulmonary veno-occlusive disease. J Heart Lung Transplant 2018; 37: $647-655$.

29 Donnelly N, Gorman AM, Gupta S, et al. The eIF2 $\alpha$ kinases: their structures and functions. Cell Mol Life Sci 2013; 70: 3493-3511. 
30 Ravishankar B, Liu H, Shinde R, et al. The amino acid sensor GCN2 inhibits inflammatory responses to apoptotic cells promoting tolerance and suppressing systemic autoimmunity. Proc Natl Acad Sci USA 2015; 112: 10774-10779.

31 Perros F, Günther S, Ranchoux B, et al. Mitomycin-induced pulmonary veno-occlusive disease: evidence from human disease and animal models. Circulation 2015; 132: 834-847.

32 Ranchoux B, Günther S, Quarck R, et al. Chemotherapy-induced pulmonary hypertension: role of alkylating agents. Am J Pathol 2015; 185: 356-371.

33 Manaud G, Nossent E, Lambert M, et al. Comparison of human and experimental pulmonary veno-occlusive disease. Am J Respir Cell Mol Biol 2020; in press [DOI: 10.1165/rcmb.2019-0015OC].

34 Troilo H, Zuk AV, Tunnicliffe RB, et al. Nanoscale structure of the BMP antagonist chordin supports cooperative BMP binding. Proc Natl Acad Sci USA 2014; 111: 13063-13068.

35 Montani D, Girerd B, Jaïs X, et al. Clinical phenotypes and outcomes of heritable and sporadic pulmonary veno-occlusive disease: a population-based study. Lancet Respir Med 2017; 5: 125-134.

36 Montani D, Lau EM, Descatha A, et al. Occupational exposure to organic solvents: a risk factor for pulmonary veno-occlusive disease. Eur Respir J 2015; 46: 1721-1731.

37 Wirbelauer J, Hebestreit H, Marx A, et al. Familial pulmonary capillary hemangiomatosis early in life. Case Rep Pulmonol 2011; 2011: 827591.

38 Dello Russo P, Franzoni A, Baldan F, et al. A 16q deletion involving FOXF1 enhancer is associated to pulmonary capillary hemangiomatosis. BMC Med Genet 2015; 16: 94.

39 Machado RD, Pauciulo MW, Thomson JR, et al. BMPR2 haploinsufficiency as the inherited molecular mechanism for primary pulmonary hypertension. Am J Hum Genet 2001; 68: 92-102.

40 International PPH Consortium, Lane KB, Machado RD, et al. Heterozygous germline mutations in BMPR2, encoding a TGF-beta receptor, cause familial primary pulmonary hypertension. Nat Genet 2000; 26: 81-84.

41 Morrell NW, Aldred MA, Chung WK, et al. Genetics and genomics of pulmonary arterial hypertension. Eur Respir J 2019; 53: 1801899.

42 Evans JDW, Girerd B, Montani D, et al. BMPR2 mutations and survival in pulmonary arterial hypertension: an individual participant data meta-analysis. Lancet Respir Med 2016; 4: 129-137.

43 Thomson JR, Machado RD, Pauciulo MW, et al. Sporadic primary pulmonary hypertension is associated with germline mutations of the gene encoding BMPR-II, a receptor member of the TGF-beta family. J Med Genet 2000; 37: 741-745.

44 Runo JR, Vnencak-Jones CL, Prince M, et al. Pulmonary veno-occlusive disease caused by an inherited mutation in bone morphogenetic protein receptor II. Am J Respir Crit Care Med 2003; 167: 889-894.

45 Assaad AM, Kawut SM, Arcasoy SM, et al. Platelet-derived growth factor is increased in pulmonary capillary hemangiomatosis. Chest 2007; 131: 850-855.

46 Kawut SM, Assaad AM, Arcasoy SM, et al. Pulmonary capillary hemangiomatosis: results of gene expression analysis. Chest 2005; 128: 575S-5766S.

47 Perros F, Montani D, Dorfmüller P, et al. Platelet-derived growth factor expression and function in idiopathic pulmonary arterial hypertension. Am J Respir Crit Care Med 2008; 178: 81-88.

48 Overbeek MJ, Boonstra A, Voskuyl AE, et al. Platelet-derived growth factor receptor- $\beta$ and epidermal growth factor receptor in pulmonary vasculature of systemic sclerosis-associated pulmonary arterial hypertension versus idiopathic pulmonary arterial hypertension and pulmonary veno-occlusive disease: a case-control study. Arthritis Res Ther 2011; 13: R61.

49 Overbeek MJ, van Nieuw Amerongen GP, Boonstra A, et al. Possible role of imatinib in clinical pulmonary veno-occlusive disease. Eur Respir J 2008; 32: 232-235.

50 Nayyar D, Muthiah K, Kumarasinghe G, et al. Imatinib for the treatment of pulmonary arterial hypertension and pulmonary capillary hemangiomatosis. Pulm Circ 2014; 4: 342-345.

51 Adachi S, Hirashiki A, Kondo T, et al. Imatinib is partially effective for the treatment of pulmonary capillary hemangiomatosis. Intern Med 2014; 53: 603-607.

52 Sato H, Sugimura K, Miura M, et al. Beneficial effects of imatinib in a patient with suspected pulmonary veno-occlusive disease. Tohoku J Exp Med 2019; 247: 69-73.

53 Ogawa A, Miyaji K, Matsubara H. Efficacy and safety of long-term imatinib therapy for patients with pulmonary veno-occlusive disease and pulmonary capillary hemangiomatosis. Respir Med 2017; 131: 215-219.

54 Maihöfer NA, Suleiman S, Dreymüller D, et al. Imatinib relaxes the pulmonary venous bed of guinea pigs. Respir Res 2017; 18: 32

55 Ghofrani HA, Morrell NW, Hoeper MM, et al. Imatinib in pulmonary arterial hypertension patients with inadequate response to established therapy. Am J Respir Crit Care Med 2010; 182: 1171-1177.

56 Hoeper MM, Barst RJ, Bourge RC, et al. Imatinib mesylate as add-on therapy for pulmonary arterial hypertension: results of the randomized IMPRES study. Circulation 2013; 127: 1128-1138.

57 Frost AE, Barst RJ, Hoeper MM, et al. Long-term safety and efficacy of imatinib in pulmonary arterial hypertension. J Heart Lung Transplant 2015; 34: 1366-1375.

58 Odronic SI, Narula T, Budev M, et al. Pulmonary capillary hemangiomatosis associated with connective tissue disease: a report of 4 cases and review of the literature. Ann Diagn Pathol 2015; 19: 149-153.

59 Diao X-L, Mu X-D, Jin M-L. Pulmonary capillary hemangiomatosis associated with crest syndrome: a challenge of diagnosis and treatment. Chin Med J 2017; 130: 2645-2646.

60 McGuire F, Kennelly T, Tillack T, et al. Pulmonary capillary hemangiomatosis associated with CREST syndrome: a case report and review of the literature. Respiration 2010; 80: 435-438.

61 Overbeek MJ, Vonk MC, Boonstra A, et al. Pulmonary arterial hypertension in limited cutaneous systemic sclerosis: a distinctive vasculopathy. Eur Respir J 2009; 34: 371-379.

62 Dorfmüller P, Humbert M, Perros F, et al. Fibrous remodeling of the pulmonary venous system in pulmonary arterial hypertension associated with connective tissue diseases. Hum Pathol 2007; 38: 893-902.

63 Fernández-Alonso J, Zulueta T, Reyes-Ramirez JR, et al. Pulmonary capillary hemangiomatosis as cause of pulmonary hypertension in a young woman with systemic lupus erythematosus. J Rheumatol 1999; 26: 231-233.

64 Kakkar N, Vasishta RK, Banerjee AK, et al. Pulmonary capillary haemangiomatosis as a cause of pulmonary hypertension in Takayasu's aortoarteritis. Respiration 1997; 64: 381-383. 
65 de Perrot M, Waddell TK, Chamberlain D, et al. De novo pulmonary capillary hemangiomatosis occurring rapidly after bilateral lung transplantation. J Heart Lung Transplant 2003; 22: 698-700.

66 Lee C, Suh RD, Krishnam MS, et al. Recurrent pulmonary capillary hemangiomatosis after bilateral lung transplantation. J Thorac Imaging 2010; 25: W89-W92.

67 Neubert L, Borchert P, Shin H-O, et al. Comprehensive three-dimensional morphology of neoangiogenesis in pulmonary veno-occlusive disease and pulmonary capillary hemangiomatosis. J Pathol Clin Res 2019; 5: 108-114.

68 Fayyaz AU, Edwards WD, Maleszewski JJ, et al. Global pulmonary vascular remodeling in pulmonary hypertension associated with heart failure and preserved or reduced ejection fraction. Circulation 2018; 137: 1796-1810.

69 Matsukuma S, Sato K. Pulmonary capillary haemangiomatosis-like lesions in severely congested lungs. Histopathology 2011; 59: 876-881.

70 Wang K-Y, Tanimoto A, Inenaga T, et al. Pulmonary capillary hemangiomatosis in chronic cardiac failure due to aortic stenosis. J UOEH 2009; 31: 339-344.

71 Jing X, Yokoi T, Nakamura Y, et al. Pulmonary capillary hemangiomatosis: a unique feature of congestive vasculopathy associated with hypertrophic cardiomyopathy. Arch Pathol Lab Med 1998; 122: 94-96.

72 Ogawa T, Ogata S, Kagami K, et al. Left ventricular noncompaction with pulmonary capillary hemangiomatosis-like lesions: case report. Cardiovasc Pathol 2019; 42: 41-43.

73 Güttinger E, Vrugt B, Speich R, et al. Reactive pulmonary capillary hemangiomatosis and pulmonary veno-occlusive disease in a patient with repaired scimitar syndrome. Case Rep Cardiol 2016; 2016: 9384126.

74 Aiello VD, Thomaz AM, Pozzan G, et al. Capillary hemangiomatosis like-lesions in lung biopsies from children with congenital heart defects. Pediatr Pulmonol 2014; 49: E82-E85.

75 Dorfmüller P, Günther S, Ghigna M-R, et al. Microvascular disease in chronic thromboembolic pulmonary hypertension: a role for pulmonary veins and systemic vasculature. Eur Respir J 2014; 44: 1275-1288.

76 Ghigna M-R, Guignabert C, Montani D, et al. BMPR2 mutation status influences bronchial vascular changes in pulmonary arterial hypertension. Eur Respir J 2016; 48: 1668-1681.

77 Carstens GR, Paulino BBA, Katayama EH, et al. Clinical relevance of pulmonary vasculature involvement in sickle cell disease. Br J Haematol 2019; 185: 317-326.

78 Xie W-M, Dai H-P, Jin M-L, et al. Clinical features and imaging findings in pulmonary capillary hemangiomatosis: report of two cases and a pooled analysis. Chin Med J 2012; 125: 3069-3073.

79 Montani D, Achouh L, Dorfmüller P, et al. Pulmonary veno-occlusive disease: clinical, functional, radiologic, and hemodynamic characteristics and outcome of 24 cases confirmed by histology. Medicine (Baltimore) 2008; 87: 220-233.

80 Saito T, Maniwa T, Kaneda H, et al. Coexistence of catamenial pneumothorax and catamenial hemoptysis in a patient with pulmonary hemangiomatosis-like foci: a case report. J Thorac Cardiovasc Surg 2010; 139: e14-e16.

81 Saito T, Saito Y, Fukumoto KJ, et al. Clinical and pathological characteristics of spontaneous pneumothorax in women: a 25-year single-institutional experience. Gen Thorac Cardiovasc Surg 2018; 66: 516-522.

82 Park MA, Shin SY, Kim YJ, et al. Vascular Ehlers-Danlos syndrome with cryptorchidism, recurrent pneumothorax, and pulmonary capillary hemangiomatosis-like foci: a case report. Medicine (Baltimore) 2017; 96 : e8853.

83 Miura A, Akagi S, Nakamura K, et al. Different sizes of centrilobular ground-glass opacities in chest high-resolution computed tomography of patients with pulmonary veno-occlusive disease and patients with pulmonary capillary hemangiomatosis. Cardiovasc Pathol 2013; 22: 287-293.

84 Laveneziana P, Montani D, Dorfmüller P, et al. Mechanisms of exertional dyspnoea in pulmonary veno-occlusive disease with EIF2AK4 mutations. Eur Respir J 2014; 44: 1069-1072.

85 Dufour B, Maître S, Humbert M, et al. High-resolution CT of the chest in four patients with pulmonary capillary hemangiomatosis or pulmonary venoocclusive disease. AJR Am J Roentgenol 1998; 171: 1321-1324.

86 Resten A, Maitre S, Humbert M, et al. Pulmonary hypertension: CT of the chest in pulmonary venoocclusive disease. AJR Am J Roentgenol 2004; 183: 65-70.

87 Bal SK, Thangakunam B, Irodi A, et al. Small sample lung biopsy findings in patients with clinicoradiologic suspicion of pulmonary venoocclusive disease-pulmonary capillary hemangiomatosis. J Bronchology Interv Pulmonol 2016; 23: 308-315.

88 Rabiller A, Jaïs X, Hamid A, et al. Occult alveolar haemorrhage in pulmonary veno-occlusive disease. Eur Respir J 2006; 27: 108-113

89 Lederer H, Muggli B, Speich R, et al. Haemosiderin-laden sputum macrophages for diagnosis in pulmonary veno-occlusive disease. PLoS One 2014; 9: e115219.

90 Galiè N, Humbert M, Vachiery J-L, et al. 2015 ESC/ERS Guidelines for the diagnosis and treatment of pulmonary hypertension: The Joint Task Force for the Diagnosis and Treatment of Pulmonary Hypertension of the European Society of Cardiology (ESC) and the European Respiratory Society (ERS): Endorsed by: Association for European Paediatric and Congenital Cardiology (AEPC), International Society for Heart and Lung Transplantation (ISHLT). Eur Respir J 2015; 46: 903-975.

91 Hadinnapola C, Bleda M, Haimel M, et al. Phenotypic characterization of EIF2AK4 mutation carriers in a large cohort of patients diagnosed clinically with pulmonary arterial hypertension. Circulation 2017; 136: 2022-2033.

92 Best DH, Sumner KL, Smith BP, et al. EIF2AK4 mutations in patients diagnosed with pulmonary arterial hypertension. Chest 2017; 151: 821-828.

93 Humbert M, Maître S, Capron F, et al. Pulmonary edema complicating continuous intravenous prostacyclin in pulmonary capillary hemangiomatosis. Am J Respir Crit Care Med 1998; 157: 1681-1685.

94 Gugnani MK, Pierson C, Vanderheide R, et al. Pulmonary edema complicating prostacyclin therapy in pulmonary hypertension associated with scleroderma: a case of pulmonary capillary hemangiomatosis. Arthritis Rheum 2000; 43: 699-703.

95 Ogawa A, Sakao S, Tanabe N, et al. Use of vasodilators for the treatment of pulmonary veno-occlusive disease and pulmonary capillary hemangiomatosis: A systematic review. Respir Investig 2019; 57: 183-190.

96 Khan NA, Khan RA, Tonelli AR, et al. Pulmonary edema following initiation of parenteral prostacyclin therapy for pulmonary arterial hypertension: a retrospective study. Chest 2019; 156: 45-52. 